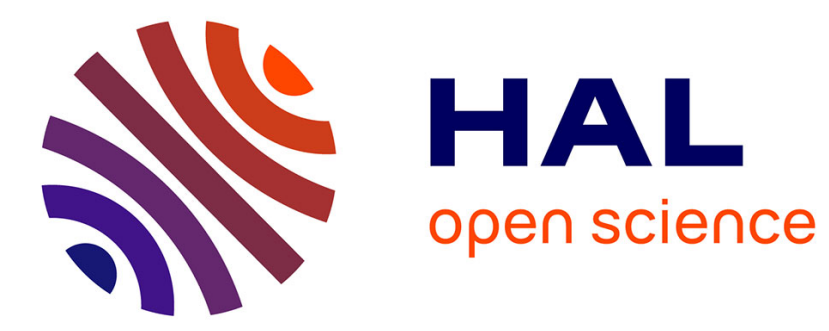

\title{
New insights on the genetic structure of lucerne with GBS markers
}

\author{
Marie Pégard, Philippe Barre, Bernadette Julier
}

\section{To cite this version:}

Marie Pégard, Philippe Barre, Bernadette Julier. New insights on the genetic structure of lucerne with GBS markers. Eucarpia - Section Fodder Crops and Amenity Grasses Meeting, Sep 2021, En ligne, Germany. hal-03323298

\section{HAL Id: hal-03323298 \\ https://hal.inrae.fr/hal-03323298}

Submitted on 20 Aug 2021

HAL is a multi-disciplinary open access archive for the deposit and dissemination of scientific research documents, whether they are published or not. The documents may come from teaching and research institutions in France or abroad, or from public or private research centers.
L'archive ouverte pluridisciplinaire HAL, est destinée au dépôt et à la diffusion de documents scientifiques de niveau recherche, publiés ou non, émanant des établissements d'enseignement et de recherche français ou étrangers, des laboratoires publics ou privés. 


\title{
New insights on the genetic structure of lucerne with GBS markers
}

\author{
Marie Pégard ${ }^{1}$, Philippe Barre ${ }^{1}$ and Bernadette Julier ${ }^{1}$ \\ ${ }^{1}$ INRAE P3F, 86600 Lusignan, France \\ marie.pegardeinrae.fr
}

\begin{abstract}
GBS markers at the population level were used to study the genetic structure of lucerne in a set of 395 accessions from Europe, North and South America and China. More than 100K SNP without missing data were obtained. The structure revealed a certain genetic distance between European and American accessions, with a continuous variation between these groups. Contrastingly, Chinese accessions were genetically separated from the other accessions. This analysis is an invitation to go more deeply into a phenotypic analysis of these genetic resources to exploit them in breeding.
\end{abstract}

Keywords: alfalfa, breeding, genetic resources, Medicago sativa L., SNP

\section{Introduction}

Lucerne (Medicago sativa L.) originates from the Middle East but is grown worldwide. As a consequence, this species is adapted to various climatic conditions, from continental to arid climate. The dissemination history of the species has been described in historical documents, phenotypic and molecular studies [1]. Briefly, it has been introduced several times in Europe with invaders (Medes and Romans through northern Mediterranean Basin and Maures through southern Mediterranean Basin), and was introduced to the Americas during the European migrations from the end of 16th century. Lucerne moved to China about 2000 years ago [2]. The cultivated forms of the ssp. sativa have naturally hybridized with the wild and cold tolerant ssp. falcata that expanded in the Siberian region.

The genotyping by sequencing (GBS) method provides numerous markers at the population level and covers the alfalfa genome. [3]. They offer a means to study the structure of the genetic resources available in this species. The current breeding programmes, conducted in Europe, America or Asia, could be improved by using a larger genetic diversity. For this reason, the objective was to describe the genetic structure of a set of 395 lucerne accessions mostly coming from Europe, North and South America and China with GBS markers. 


\section{$2 \quad$ Material and methods}

In this study, we used 395 accessions comprised of 373 cultivars and 22 landraces whose autumn dormancy was mainly among 3 and 7 on a scale of 1 to 9 ( 1 slightly dormant and 9 very dormant). Their origin, based on the place they have been collected (landraces) or initially selected and registered (cultivars) was Europe (313 accessions), North America (45 accessions), South America (16 accessions), China (17 accessions), Middle East (3 accessions) and Japan (1 accession). The accessions were genotyped by GBS [4]. A subset of SNP without any missing value was sorted out to avoid an imputation step and only SNPs with a minor allelic frequency higher than $1 \%$ were kept, $118 \mathrm{~K} \mathrm{SNP}$ were obtained. These genomic data were used to identify genetic clusters among these populations with the Discriminant Analysis of Principal Components (DAPC) method. The number of retained PC was fixed at 300, this number represented the number of PC that explained $90 \%$ of the variation. The genetic clusters were identified by using k-means, a clustering algorithm which found a given number $(\mathrm{k})$ of groups by maximizing the variation between groups. The optimal number of clusters was the one that provided the lowest Bayesian Information Criterion (BIC), here seven. We then run a Principal Component Analysis (PCA). The accessions were grouped by using either the seven groups defined from DAPC analysis or an a priori classification into six groups based on the geographical origin of the accessions: "Europe", "North America", South America", "China", "Middle East", "Japan".
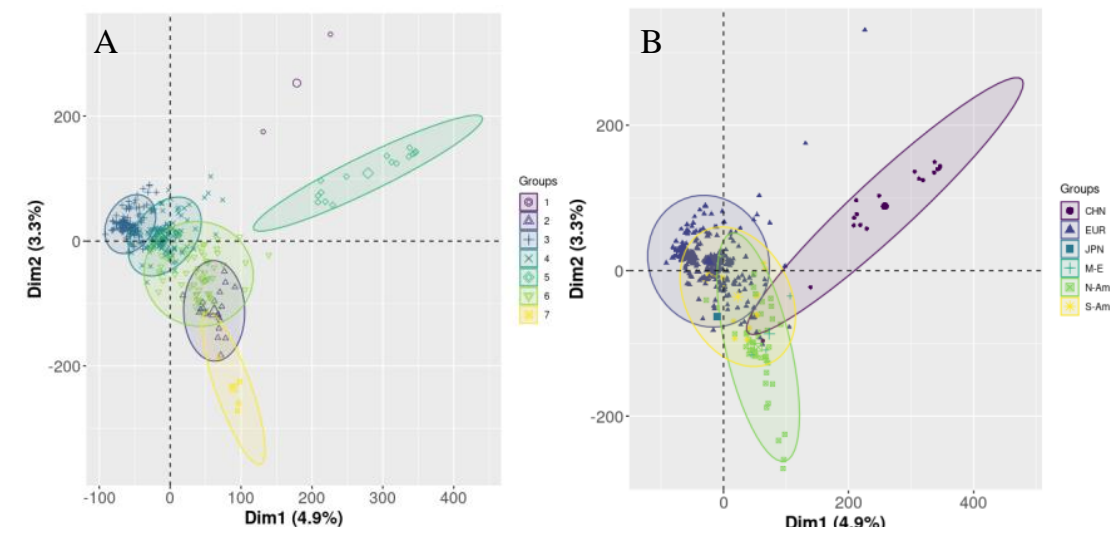

Fig. 1. Graphical representation of the first two dimensions of a principal components analysis for lucerne accessions. PC1 and PC2 explained $4.9 \%$ and $3.3 \%$ of total genetic variation. A: each group found with the DAPC procedure is in a different color. B: the individuals are colored according to their geographical origin; CHN: China, EUR: Europe, JPN: Japan, M-E: Middle-Est, N-Am: North America, S-Am: South-America. 


\section{Results}

The Fig. 1 (A) represents the PCA with the accessions colored according to the seven DAPC groups. Two groups were clearly separated from the others: group 6 with 15 Chinese accessions and group 1 with two accessions only (a falcata type from Italy and a Hungarian variety). The five other groups showed a genetic continuum: group 3 with 139 accessions of European origin only (France and Northern Europe), group 7 with 151 accessions mostly of European origin (Southern and Eastern Europe), group 4 with 61 accessions of Europe, North and South America), group 5 with 21 USA and 1 Chinese accessions and group 2 containing 5 North-American accessions only. The European accessions as well as the American accessions were splitted into several groups. The group 4 probably illustrates the multiple origins of some varieties selected in the two continents.

When the clustering was based on the geographical origin of the accessions (Fig. 1 (B)), the Chinese accessions were again mostly separated from all other origins. The European and the North-American accessions had little overlapping, but SouthAmerican accessions interestingly overlapped these two groups. The three accessions from the Middle East were close to the American accessions and the Japanese accession was closer to the European-American groups than from the Chinese group.

The structure obtained in this study shows that breeding programmes conducted in Europe partly ignore genetic resources from North and South America even if there is a continuous variation among groups. Contrastingly, there is an almost complete separation among European-American accessions on one side and Chinese accessions on the other side. In this material, the autumn dormancy rating, when known, is not a relevant classification key (not shown). This analysis is an invitation to go more deeply into a phenotypic analysis of these genetic resources to exploit them in breeding. Further historical analysis of lucerne expansion in the world could be also interesting.

\section{Acknowledgements}

This study was supported by EUCLEG project (UE, H2020 n727312). We thank Sabrina Delaunay and Sébastien Blugeon for their contribution to genotyping and the Centre of Biologic Resources of INRAE (URP3F). We also thank all the institutes and breeding companies that accepted to include their varieties in this study.

\section{References}

1. Prosperi, J.M., Muller, M.H., Ronfort, J., Fourtier, S., Sampoux, J.P., Jenczewski, E..: Alfalfa domestication history, genetic diversity and genetic resources. Legume Perspectives 4, 13-14 (2014)

2. Basigalup, D., Irwin, J., Mi, F., Abdelguerfi-Laouar, M.: Perspectives of alfalfa in Australia, China, Africa and Latin America. Legume Perspectives 4, 9-10 (2014). 
3. Julier, B., Barre, P., Lambroni, P., Delaunay, S., Thomasset, M., Lafaillette, F., Gensollen, V.: Use of GBS markers to distinguish among lucerne varieties, with comparison to morphological traits. Mol. Breed. 38, 133 (2018).

4. Julier, B., Blugeon, S., Delaunay, S., Mappa, G., Ruttink, T., Pégard, M., Barre, P.: Optimisation of GBS protocols for efficient genotyping of forage species. Eucarpia Forage Crops and Amenity Grasses section, submitted (2021). 